\title{
New APProach of Measuring Toxic GaSeS CONCENTRATIONS: PrinCiPLE OF OPERATION
}

\author{
Adnan Masic, Dzevad Bibic, Boran Pikula \& Faruk Razic
}
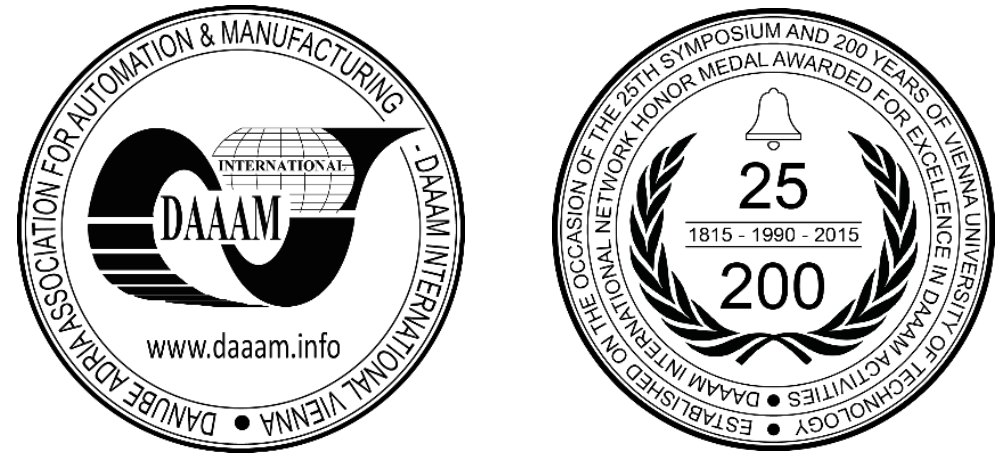

This Publication has to be referred as: Masic, A[dnan]; Bibic, D[zevad]; Pikula, B[oran] \& Razic, F[aruk] (2018). New Approach of Measuring Toxic Gases Concentrations: Principle of Operation, Proceedings of the 29th DAAAM International Symposium, pp.0882-0887, B. Katalinic (Ed.), Published by DAAAM International, ISBN 978-3-90273420-4, ISSN 1726-9679, Vienna, Austria

DOI: $10.2507 / 29$ th.daaam.proceedings.127

\begin{abstract}
Measurement of the concentrations of toxic gases (such as $\mathrm{CO}, \mathrm{SO}_{2}, \mathrm{NO}_{\mathrm{X}}$ and $\mathrm{O}_{3}$ ) in the air represent important but challenging task. Traditionally, these concentrations are measured by means of heavy and expensive toxic gas monitors, usually operated by the governmental institutions. In this paper we present a novel method based on commodity (lowcost) electrochemical sensors and in-house developed data acquisition system. Principle of operation is explained, together with the calibration procedure and initial evaluation of sensors' performance. Possible applications are discussed as well.
\end{abstract}

Keywords: air pollution; toxic gas concentration; electrochemical sensor; temperature drift; amperometric cell

\section{Introduction}

According to the World Health Organization (WHO), 4.2 million people die every year due to the ambient air pollution and 3.8 million more as a result of household exposure to smoke from dirty cookstoves and fuels, while $91 \%$ of the world's population lives in places where air quality exceeds WHO guideline limits [1]. An important step towards the solution of the problem of air pollution is monitoring of the concentrations of toxic gases in the air. However, vast majority of the population affected by the excessive air pollution live in developing countries [2]. Hence, affordable and reliable methods for monitoring of toxic gases are urgently needed. A very promising approach is to use commodity electrochemical sensors [3], recently developed by Alphasense Ltd (UK).

Alphasense toxic gas sensors are electrochemical cells that operate in the amperometric mode. They generate a current that is linearly proportional to the fractional volume of the toxic gas [4]. Electrochemical amperometric gas sensors have a background current in addition to the current from oxidation or reduction of the sampled gas. This background current is commonly called the zero current. These zero currents can be significant in the measurements at low gas concentrations. Sources of these zero currents can include anodisation or cathodic reduction of the working electrode (WE), electrochemical oxidation or reduction of the sensor electrolyte or electrolyte contaminants by the WE and reduction of oxygen in the sampled air [5]. 
In order to correct for zero currents, the Alphasense sensors include an additional electrode, an auxiliary electrode (AE), buried within the sensor. The AE has the same catalyst structure as the working electrode (WE) so, in principle, since it is not in contact with the sampled gas, any background current arising from solid electrode processes or from electrochemistry involving the electrolyte will be measured on both the WE and the AE. This AE current could then be subtracted from the WE total current to give a corrected WE current corresponding solely to the electrochemical reaction of the sampled gas [5].

\section{The test setup}

We have acquired and analysed the following Alphasense sensors:

- SO2-B4, range (0-100) ppm,

- CO-A4, range (0-500) ppm,

- NO-A4, range (0-20) ppm,

- NO2-A4, range (0-20) ppm,

- OX-A4, range (0-20) ppm.

Sensor SO2-B4 was installed on Alphasense ISB (Individual Sensor Board), while A-type sensors were combined on one 4-way AFE (Analogue Front End) board from Alphasense. ISB and AFE boards contain electronic components which convert small currents from electrochemical cells to the buffered voltage (0-5) V, which is more suitable for interfacing and integration into DAS (Data Acquisition System). Our DAS is in-house developed and based on previous work described in [6], [7] and [8].

Taking into account voltage range and typical sensor sensitivities, we arrive at conclusion that at least 16-bit ADC (Analogue to Digital Converter) is necessary. We have chosen ADS1115 from Texas Instruments (USA) as suitable ADC for Alphasense sensor boards. This is 4-channel 16-bit ADC with I2C interface, which can be easily connected to various microcontrollers, such as Arduino. The Figure 1 shows simplified schematics of our platform. Since we have 5 electrochemical sensors, we need at least 10 ADC channels (working and auxiliary electrode voltage for each sensor). Thus, three ADS1115 devices are required. Data storage is flash memory card, which communicates with the Arduino over SPI bus. The OX sensor reacts to ozone $\left(\mathrm{O}_{3}\right)$ and nitrogen dioxide $\left(\mathrm{NO}_{2}\right)$; together with $\mathrm{NO}_{2}$ sensor, we can calculate results for $\mathrm{O}_{3}$ alone.

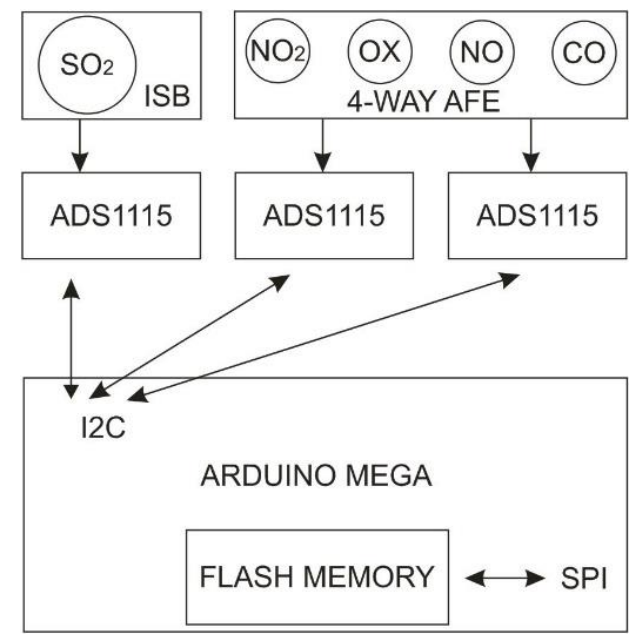

Fig. 1. Simplified schematics

\section{Results}

Five electrochemical sensors, together with electronic boards and DAS as described above, were installed at the Federal Institute for Hydrometeorology in Sarajevo, Bosnia-Herzegovina, in order to assess sensors' performance and key characteristics. System was continuously running from 18-05-2018 until 22-06-2018. One minute average values from the sensors were logged to the flash memory. Primary goal of the experiment was investigation of temperature drifts of both working and auxiliary electrode and noise levels. The Figure 2 shows auxiliary electrode voltage (one minute average) vs. temperature for all sensors. We can see that $\mathrm{SO}_{2}$ and $\mathrm{NO}$ boards show parabolic-like temperature dependence in the interval (15-35) ${ }^{\circ} \mathrm{C}$ (second-order polynomial was fitted in the corresponding graphs), while other sensors do not show clear trend. Assessing the working electrode was much more difficult, since it reacts to target gas, whose concentration is not known. However, reference monitors were available at the Federal Institute for Hydrometeorology, so we could detect periods of clean air, with near-zero concentration of the target gas. Figure 3 shows working electrode zero values vs. temperature for all sensors. 

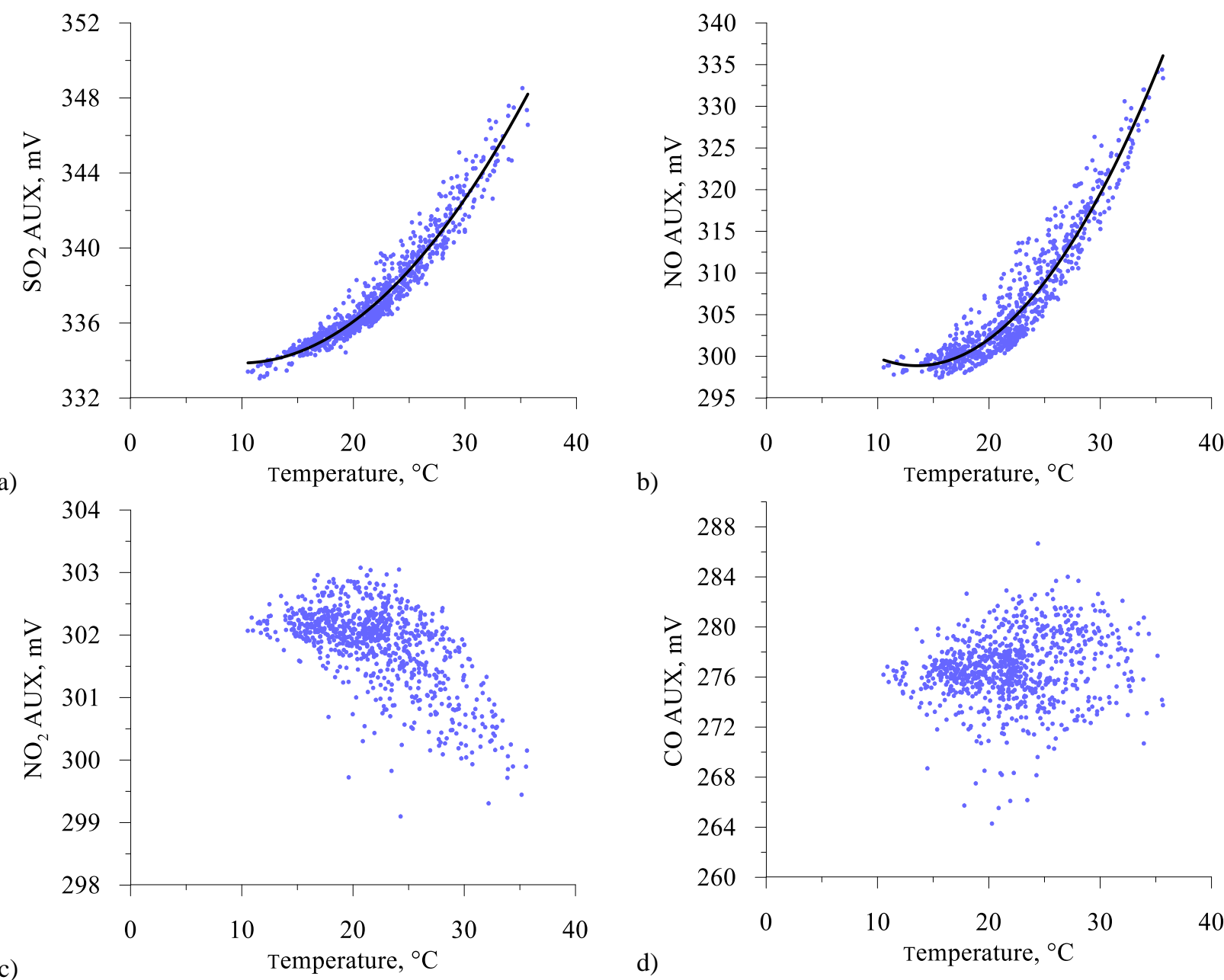

b)
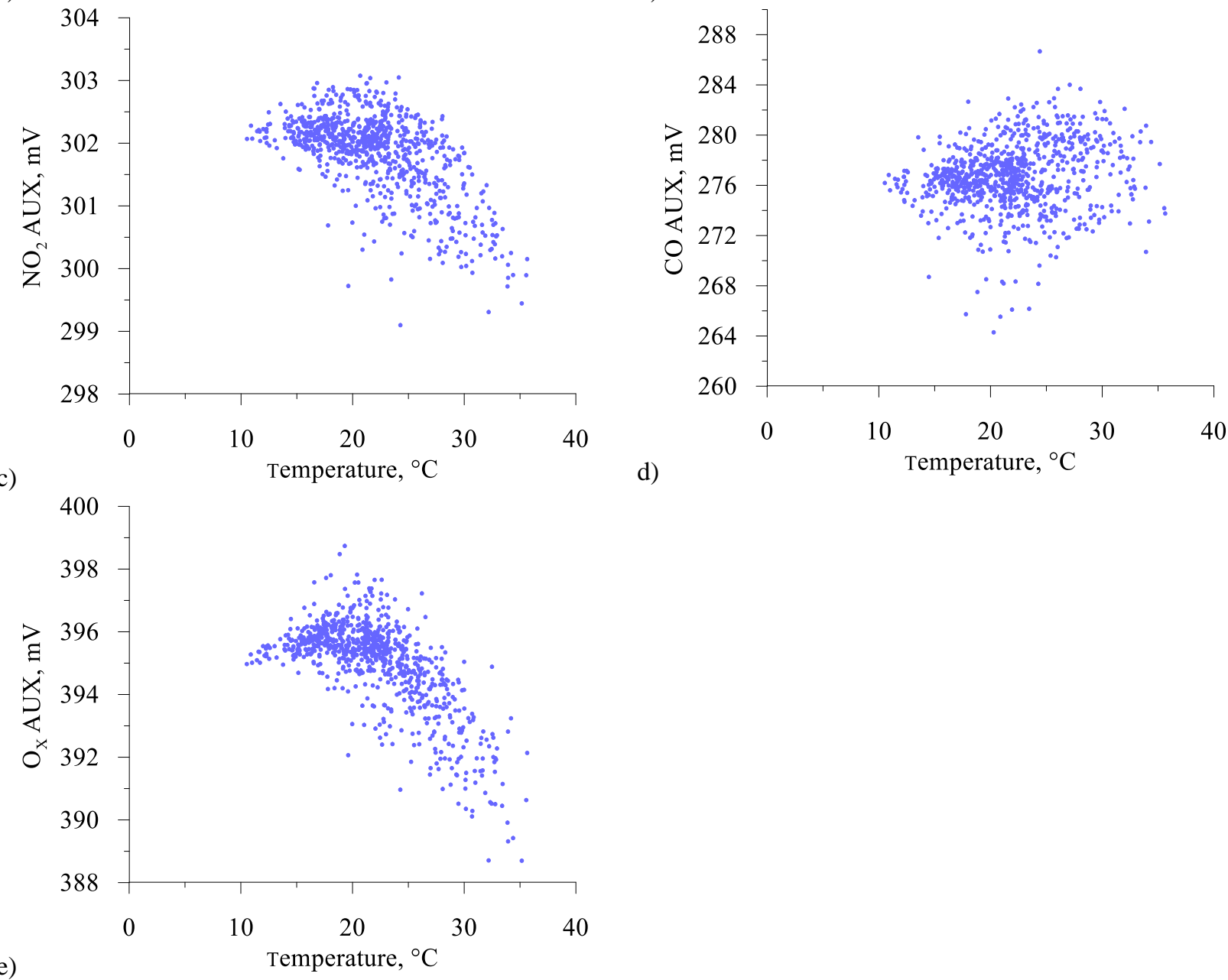

Fig. 2. Temperature drift of auxiliary electrodes of used sensors for $\mathrm{SO}_{2}, \mathrm{NO}, \mathrm{NO}_{2}, \mathrm{CO}, \mathrm{O}_{\mathrm{X}}$

This time $\mathrm{SO}_{2}$ sensor follows linear trend of dependence of working electrode zero vs. temperature, while NO sensor follows polynomial fit of second order. This statement is not firm (as in the case of auxiliary electrode), since the zero concentration of target gas couldn't be verified. Other sensors do not show clear trends, again.

To conclude this part, it seems that for room temperatures, $(20-25){ }^{\circ} \mathrm{C}$, the working electrode zero and the auxiliary electrode zero may be taken as constants for each sensor (with board). In the wider temperature range, corrections for $\mathrm{SO}_{2}$ and NO may be necessary, though. By looking at the schematics in the Figure 1 (and knowing the nature of amperometric cells), it is clear that the noise would be a great problem. Before we present new graphs, let's clarify how concentration $c$ of the target gas is actually calculated. We measure two voltages from each sensor/board: working electrode voltage ( $U_{\mathrm{WE}}$ ) and auxiliary electrode voltage $\left(U_{\mathrm{AE}}\right)$. We must subtract zero values, $U_{\mathrm{WE} 0}$ and $U_{\mathrm{AE} 0}$ and divide the difference by sensitivity of the sensor $s$ : 


$$
c=\frac{\left(U_{W E}-U_{W E 0}\right)-\left(U_{A E}-U_{A E 0}\right)}{s}
$$

Using equation (1), we get volume concentrations (measured in ppb). If we want the mass concentration $c_{\mathrm{m}}\left(\mathrm{in} \mu \mathrm{g} / \mathrm{m}^{3}\right.$ ), we can use the following conversion:

$$
c_{m}=c \cdot \frac{p M}{R T}
$$

where $p$ is the pressure, $M$ is the molar mass, $R$ is the universal gas constant and $T$ is the temperature.

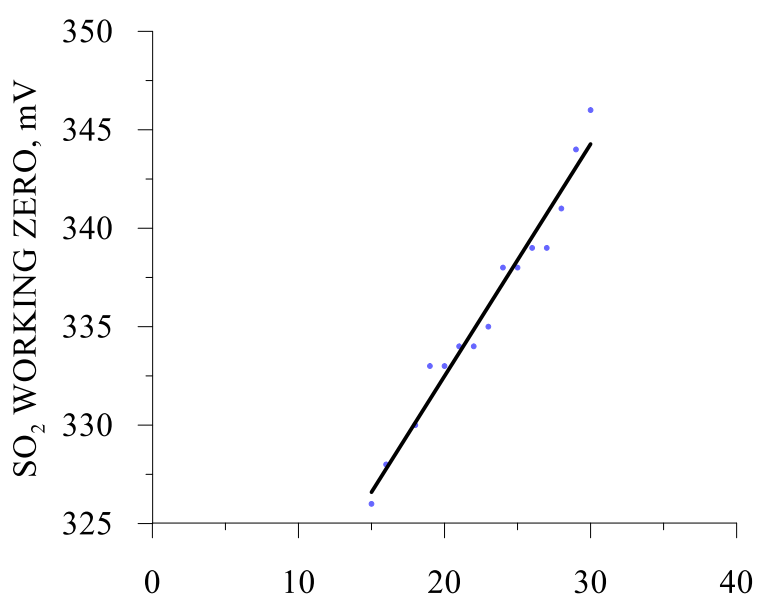

a)

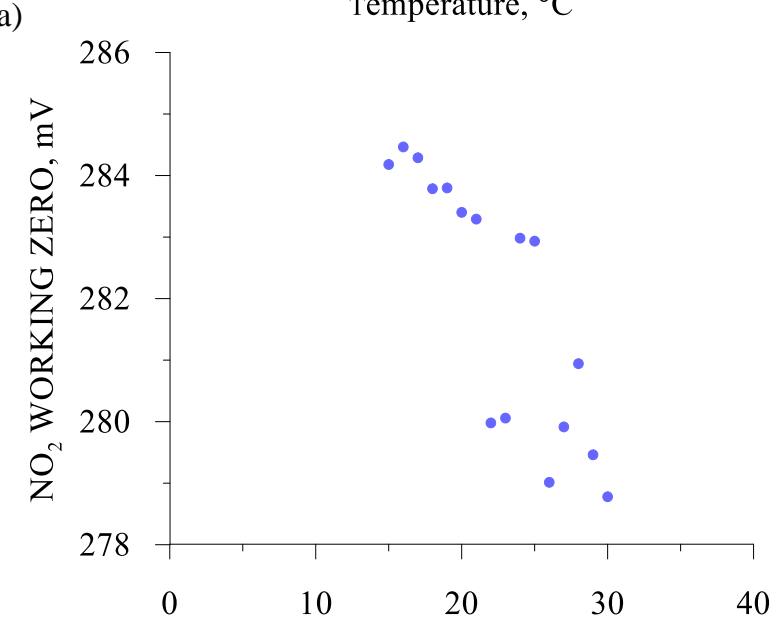

c)

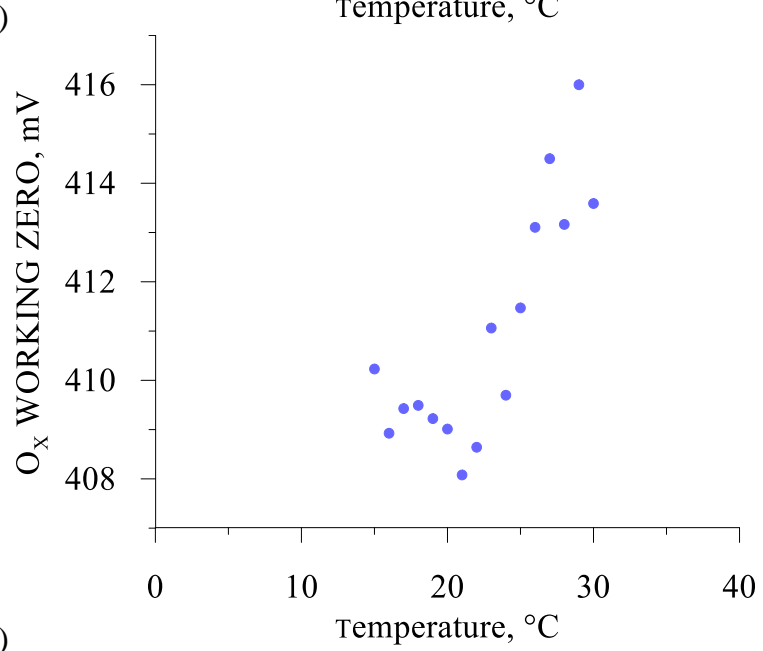

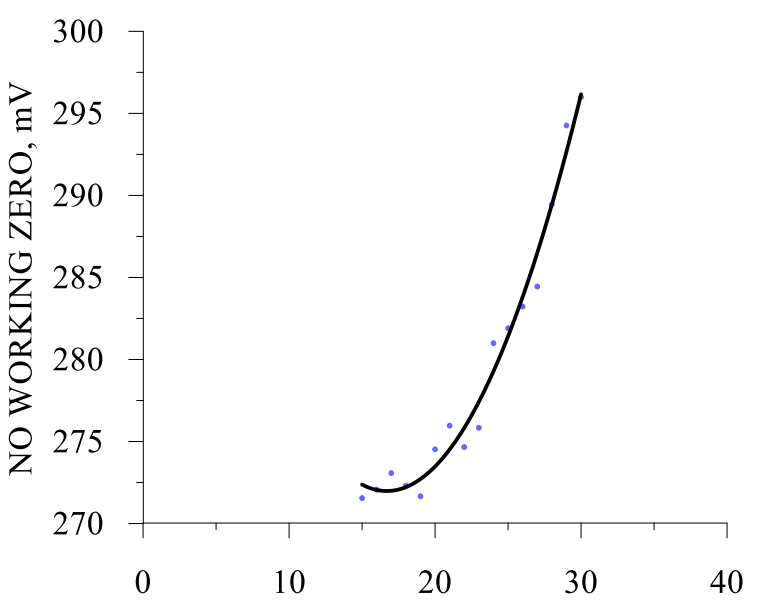

b)

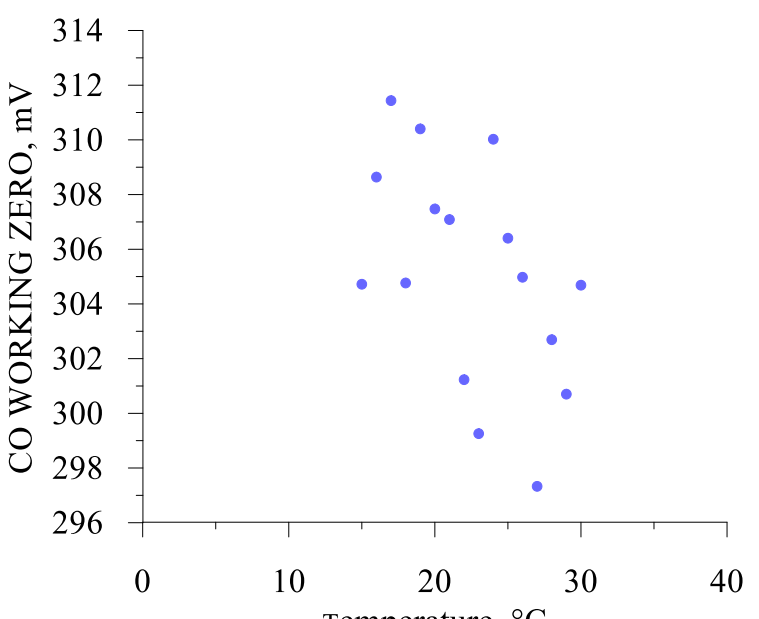

d)

Temperature, ${ }^{\circ} \mathrm{C}$

Fig. 3. Temperature drift of working electrode of used sensors for $\mathrm{SO}_{2}, \mathrm{NO}, \mathrm{NO}_{2}, \mathrm{CO}, \mathrm{O}_{\mathrm{X}}$ 
According to the manufacturer's recommendation, we have soldered capacitors of $10 \mathrm{nF}$ and $100 \mathrm{nF}$ close to the power supply connectors of both ISB and AFE boards, in order to minimize noise injection (Figure 4).

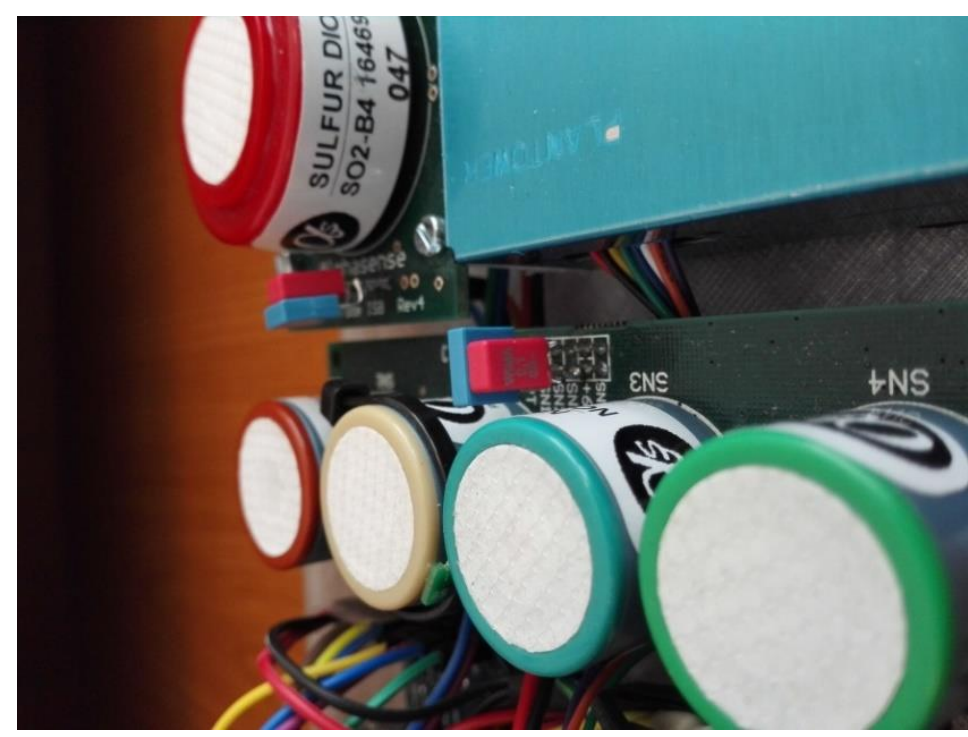

Fig. 4. Decoupling capacitors on AFE and ISB boards with sensors

Despite this effort, noise appears on all measurements, to some extent. The Figure 5 shows almost instantaneous readings (sampling period was 3 seconds) from one typical run of $\mathrm{SO}_{2}$ sensor. Noise of few $\mathrm{mV}$ in the signal from electrodes exists, which translates into few tens of ppb in volume concentration. Black line in the Figure 5 is smoother (moving average trend line with 15 samples per move). Noise may be minimized using combination of hardware (filters) and software (processing of the signal), but it turns out that these sensors are not suitable for very low concentrations of target gas.

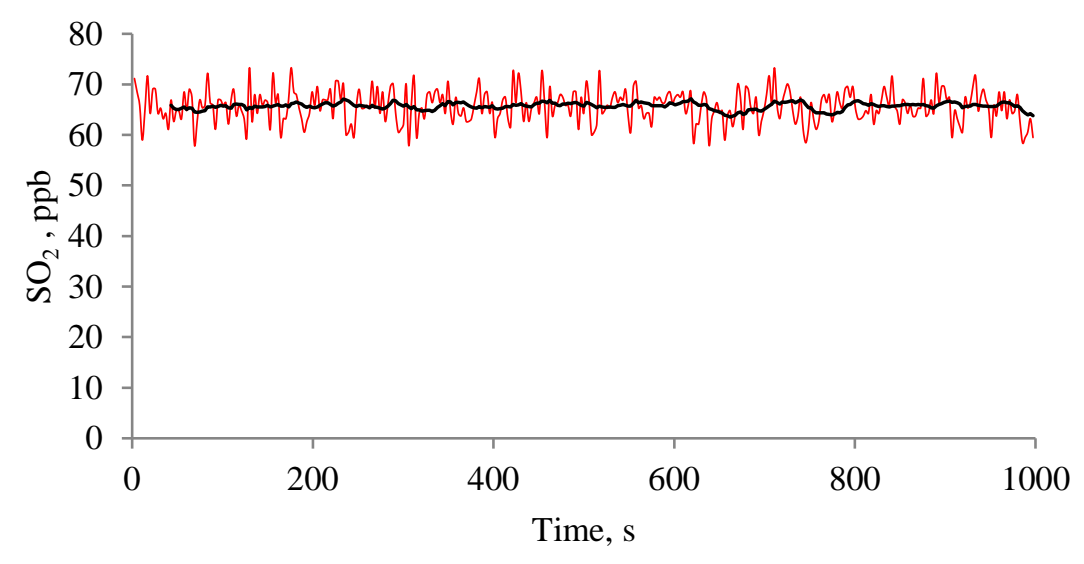

Fig. 5. Noise on $\mathrm{SO}_{2}$ sensor

\section{Conclusion}

Electrochemical amperometric sensors, such as Alphasense 4-electrode sensor family, together with appropriate interface and data acquisition system, represent promising, new technology for measuring the concentrations of toxic gases in the air. However, their use is not straight-forward. Each sensor must be (individually) calibrated. Signals from the electrodes should be corrected for (non-trivial) temperature drifts, sensitivities of individual sensors are also temperature dependant and decay over time. There is also cross-sensitivity problem [9], which is difficult to deal with. The noise in the signals from electrodes (amplified using circuit boards) are especially problematic in case of low concentrations of toxic gases.

As a suggestion for further research we propose:

- Application of electrochemical sensors to real-life problems, such as air pollution in underground garages or realtime street measurements,

- Investigation of sensitivity of the sensor over longer periods,

- Investigation and modelling of the cross-sensitivity. 


\section{Acknowledgments}

This research was supported by the Ministry of Education of Sarajevo Canton and the University of Sarajevo - Faculty of Mechanical Engineering. We would like to express gratitude to the Federal Institute for Hydrometeorology as well. The Last but not the least, we would like to thank to Mr. Damir Muslic for his generous contribution to our project by writing core part of the in-house developed software.

\section{References}

[1] http://www.who.int/airpollution/en/, (2018). World Health Organization, Accessed on: 2018-09-23

[2] Kumar, R. (2018). Five steps to improve air-quality forecasts. Nature, 561 (2018) 27-29

[3] Mead, M. I.; Popoola, O. A. M.; Stewart, G. B.; Landshoff, P.; Calleja, M.; Hayes, M.; Baldovi, J. J.; McLeod M. W.; Hodgson T. F.; Dicks J.; Lewis A.; Cohen J.; Baron R.; Saffell J. R. \& Jones, R. L. (2013). The use of electrochemical sensors for monitoring urban air quality in low-cost, high-density networks. Atmospheric Environment, 70 (2013) 186-203

[4] How electrochemical gas sensors work (2013). Alphasense Application Note AAN 104

[5] Correcting for background currents in four electrode toxic gas sensors (2017). Alphasense Application Note AAN 803-04

[6] Masic, A. (2015).Unmanned Aerial Vehicle as Data Acquisition System. Journal of Trends in the Development of Machinery and Associated Technology. Vol. 19, No. 1, 2015, ISSN 2303-4009 (online), 181-184

[7] Masic, A.; Musemic, R. \& Dzaferovic-Masic, E. (2016). Temperature Inversion Measurements in Sarajevo Valley Using Unmanned Aerial Vehicles, Proceedings of the 27th DAAAM International Symposium, pp.0423-0427, B.Katalinic (Ed.), Published by DAAAM International, ISBN 978-3-902734-08-2, ISSN 1726-9679, Vienna, Austria, DOI: 10.2507/27th.daaam.proceedings.062

[8] Masic, A.; Pikula, B. \& Bibic, Dz. (2017). Mobile Measurements of Particulate Matter Concentrations in Urban Area, Proceedings of the 28th DAAAM International Symposium, pp.0452-0456, B. Katalinic (Ed.), Published by DAAAM International, ISBN 978-3-902734-11-2, ISSN 1726-9679, Vienna, Austria, DOI: 10.2507/28th.daaam.proceedings.063

[9] Cross E. S.; Williams, L. R.; David K.; Lewis, D. K.; Magoon G. R.; Onasch T. B.; Kaminsky, M. L.; Worsnop, D. R. \& Jayne, J. T. (2017). Use of electrochemical sensors for measurement of air pollution: correcting interference response and validating measurements, Atmospheric Measurement Techniques, 10 (2017) 3575-358, DOI: 10.5194/amt-10-3575-2017 